\title{
Modeling the Efficiency of Implementation of Energy Saving Policy at Enterprises under Uncertainty Conditions
}

\author{
Mykhaylo Voynarenko \\ First vice-rector, vice-rector for \\ scientific-pedagogical and scientific \\ work \\ Khmelnytskyi National University \\ Khmelnytskyi, Ukraine \\ voynarenko@ukr.net \\ http://orcid.org/0000-0002-1301-1492
}

\author{
Viacheslav Dzhedzhula \\ Department of Finances and Innovative \\ Management \\ Vinnytsia National Technical \\ University \\ Vinnytsia, Ukraine \\ djedjulavv@gmail.com \\ http://orcid.org/0000-0002-2740-0771
}

\author{
Iryna Yepifanova \\ Department of Finances and Innovative \\ Management \\ Vinnytsia National Technical \\ University \\ Vinnytsia, Ukraine \\ epifanovairene@gmail.com \\ http://orcid.org/0000-0002-0391-9026
}

\begin{abstract}
In the article a mathematical model of the intellectual support of decision making for the evaluation of the efficiency of implementation and operation of energy saving policy of the enterprise under uncertainty conditions with the help of Mat Lab's mathematical package has been developed. The main factors influencing the decision making process regarding the feasibility of implementing energy saving policy at the enterprise have been determined. The aim of the work is to develop expert-modeling system of decision making support for evaluation of the efficiency of energy saving policy under conditions of uncertainty and risk. With the help of the developed system, there has been made the evaluation of the efficiency of the implementation of energy saving policy at Ukrainian enterprises. It has been revealed that the most important factors determining the efficiency of implementation and realization of energy saving policy at the enterprises belonging to the same industry are internal factors and the cost of external sources of financing.
\end{abstract}

Keywords - energy saving, efficiency, uncertainty, hybrid neural networks, neuro-fuzzy neural network

\section{INTRODUCTION}

The development of an enterprise in the market economy system requires the use of innovative approaches. Operation of any production takes place using energy resources for the manufacture and support of the life of the enterprise itself. Metallurgical, machine-building, manufacturing, light industries are the most energy-intensive productions. The basis of state policy in energy saving is a set of normative legal acts aimed at forming a certain set of actions for reducing the consumption of primary and transformed energy resources. The energy saving policy of an enterprise should be an integral part of the general development strategy. The functioning of a modern enterprise takes place under conditions of uncertainty and risk, there is a significant influence of external and internal factors - the stability of the national currency and the political situation, the state of markets of energy consulting services and energy saving technologies, the level of qualification and motivation of the enterprise personnel, etc. The improvement of profitability, competitiveness and energy efficiency of the enterprise should take place at the expense of innovative measures. To ensure the economic stability of the enterprise it is quite important to manage energy saving actively, the first stage of which should become the formation of energy saving policy at the enterprise. The implementation of individual, local energy saving measures at the enterprise will not contribute to a qualitative increase in the energy efficiency of the enterprise. To achieve sustainable effect and significant qualitative changes, a complex of actions is required which are aimed at increasing the energy efficiency of production by implementing energy saving measures, organizational and structural changes, i.e. energy saving policy.

\section{LITERATURE REVIEW}

Such scientists as V. M. Heyets [1], B. P. Gevko, V. Ya. Brich, B.V. Pogrischuk, Yu.V. Dzyadykevych and A. M. Alileuko [2], V.V. Stadnyk [3; 4], V. M. Nyzhnyk [5] and others are engaged in researches on energy saving problems and formation of energy saving policy.

A large number of scientists are investigating issues related to energy saving and management of energy saving. The efficiency of energy use is considered as one of the most cost-effective options for reducing the impact of growing demand for energy resources and achieving the goal of reducing greenhouse gas emissions [6]. Enterprises seek to identify methods to increase energy efficiency and safe energy use [7]. The world urgent needs encourage enterprises to implement both individual energy-saving measures and use a systematic approach to improving the overall energy efficiency of an enterprise and enhancing its competitiveness [8].

Mykytenko V. V. substantiated that energy efficiency reflects the property of industrial production, technologies, complex systems and characterizes the volume of output per unit of consumed energy [9].

It is very important to understand current energy saving management issues and the factors that influence this management, because without a clear understanding of the existing difficulties, the policy may be ineffective [10].

Păunescu C. and Blid L. suggest designing a sustainable energy management system at the enterprise using the PlanDoCheck-Act approach. The authors analyzed the efficiency of enterprises' energy goals, the quality of the energy efficiency indicator, and proposed an example of an action plan for reducing energy consumption [11].

Kostin Yu. D., Bezlepkin V. M. considered the issue of development of a substantiated system of measures for the formation and evaluation of energy saving potential of 
enterprises of the fuel and energy complex, which should be adequate to the company's capabilities and achieved level of energy consumption [12].

Kyrylenko O. V. defines the concept of "energy strategy" as a process of formation of the general perspective direction of the enterprise development of in the field of energy saving on the basis of the definition of qualitatively new goals, the coordination of internal capabilities of the enterprise with the environment and the development of a complex of energy saving measures that ensure its implementation [13].

Deterministic, statistical, expert and combined methods are the most often used to solve the task of multifactorial modeling of the process of energy saving management of an industrial enterprise. The linear and non-linear optimization methods are the most widespread, but the use of these methods requires a quantitative and clear nature of the input quantities. The Bayesian approach to modeling is based on the Bayesian theorem on the posterior probabilities of predicted information, and, according to Pearl J. [14], has a number of limitations: the need for a significant amount of statistical experimental information, the absence of the repeat of input factors in different forecasts. Zade D. [15], Kulazhenko V. V. [16] and Matviychuk A. V. [17] offer the use of modern models based on the theory of artificial neural networks, and allow approximating different processes. The main property of artificial neural networks is the ability to learn, based on a sample of experimental data. Some of the neural networks mimic the work of human brain cells. The upstream resultant signal from the neuron depends on the weighted amount of input signals, so the use of artificial neural networks for intelligent support for decisions on energy efficiency of industrial production requires a huge selection of experimental data that have not been accumulated yet.

At the same time, the issue of evaluation of the efficiency of implementing energy saving policy under uncertainty conditions, in particular through the device of hybrid neural networks, remains poorly developed.

The aim of the work is to develop expert-modeling support system of decision making for assessing the efficiency of energy saving policy under conditions of uncertainty and risk.

\section{STUDY METHOD}

Theoretical and methodological basis of scientific research is general scientific principles, dialectical method of scientific knowledge, fundamental positions of modern economic theory, modern concepts of energy saving management, laws of social development, legislative and normative documents, scientific works of domestic and foreign scientists. For solving the tasks, there have been used abstract-logical analysis, classification-analytical analysis and comparative analysis for research of the set of factors of influence on the level of intellectual capital as a factor of efficiency of management of energy saving; methods of heuristic forecasting: expert surveys for the formation of knowledge bases of the proposed mathematical model based on the theory of fuzzy logic, linguistic variable and hybrid neural networks; pair comparison - for the construction of membership functions; logical generalizations - to formulate the conclusions of the study.

\section{results and discussion}

The basis for creating energy saving policy at the enterprise is the creation of a system of energy management, carrying out an economic-energy survey, implementation of the organizational and economic mechanism of energy saving. Any business entity operates in the economic system and feels both the external influence of this system and the internal one, and must be able to adapt to existing and possible changes in the external environment. The external environment, which is a dynamic system, is characterized by constant changes. That is why it is not companies that are able to form a successful energy saving policy, but those that can adapt it in time to changes and take risks into account can achieve success.

The process of risks taking involves identifying them, determining the possible measure of the impact on the process of implementation of energy saving policy, assessing the level of influence on the activity of the enterprise and finding ways to reduce the risks or neutralize them.

Accordingly, the process of forming a policy of energy saving at the enterprise will be significantly influenced by various factors that we believe can be divided into three main groups: external factors of indirect influence, external factors of direct influence, and internal factors of direct influence. Due to the fact that the formation of energy saving policy takes place under conditions of uncertainty and risk, the task is to create a system of intellectual support of decision making. This system will provide an opportunity to evaluate the efficiency of implementing energy saving policy (ESP) at the enterprise under the given conditions and determine the feasibility of introducing ESP at this stage.

In our opinion, taking into account [17-20], external factors of indirect influence can include: favorable legislation; the stability of the political situation; the state of the market of energy consulting services; the stability of the national currency. These factors have no direct impact on the implementation of energy saving policy, but thus form the environment for the development of the enterprise in this direction. Without a regulatory framework, it is not possible at all to focus on energy saving and the level of favorableness, detailing and legislative coverage has an indirect effect on energy saving policy at the enterprise. The unfavorable political situation, instability in the state reduces the level of investment attractiveness of energy saving measures and forces management of the company to refuse to introduce energy-efficient solutions in favor of more pressing problems. Energy consulting services are provided to the management of enterprises for the purpose of intellectual support of decision making on energy saving. Usually this support is provided in the form of recommendations based on the results of energy audit or more extensive research - economic and energy survey. Without the involvement of outsiders, the company usually does not have the power to carry out the entire complex of energy surveys on its own, and most importantly - to provide objective information on the level of energy consumption and the inefficient use of energy resources. Subjectivity and interest of some employees of the enterprise in the conclusions necessitate the involvement of experts from third-party energy consulting companies. 
The external factors of direct influence include the following: development of the market of energy-saving technologies; the cost of external sources of financing; stimulation by the state; the level of demand for the products of the enterprise. Depending on the development of the market for energy saving technologies, the enterprise has an opportunity to bring energy-saving technologies into the production cycle or, in general, to the process of energy consumption. The state may provide certain incentives for the development of energy saving projects at enterprises in the form of grants, subsidies, tax breaks and others. The cost of external sources of financing is an extremely important factor of influence on the energy saving policy of the enterprise, as most enterprises are not able to fully finance energy-saving projects on their own. The attraction of external financing is possible only with such a cost of external sources, which will ultimately make the project cost-effective. But with a low level of demand for products, management can abandon energy-efficient solutions altogether, as low demand generates low income, and accordingly, enterprises will not have the funds to repay loans that will be involved in energy saving.

The internal factors of direct influence are the most important factors. In our opinion, they can be divided into the following groups: level of personnel qualification; personnel motivation for energy saving; presence or absence of their own financial resources, management efficiency. Implementation of energy-efficient solutions can take place only at the appropriate level of qualification of the personnel of the enterprise.

Unskilled and non-motivated employees will not actively contribute to the implementation of energy saving measures. In order to reduce the risks of financing such projects, it is desirable for the enterprise to use as much as possible of its own financial resources, as this reduces the risks of not achieving the expected financial effect. Efficiency of management is one of the most important links in the structure of implementation of energy saving measures. A well-defined capital structure to finance these activities, the duly organized work and motivation of staff, the involvement of energy consulting companies - all these are the responsibility of management.

Forecasting the efficiency of implementing energy saving policy at the enterprise under conditions of uncertainty of external and internal influences requires a mathematical model of intellectual support of decisions, based on a set of key qualitative and quantitative factors of influence on this process. A mathematical apparatus based on the theory of fuzzy logic and hybrid neural networks has been used to create an expert-modeling system for multifactorial analysis of decision-making processes for assessing the efficiency of energy saving policies of enterprises. This method, as a set of mathematical models, algorithms and formalized methods, allows using expert, experimental, analytical information to predict the efficiency of implementing energy policy at the enterprise [15]. Models formed by this mathematical apparatus allow us not only to use knowledge of experts, but also to further learn using knowledge bases obtained during the enterprise activity. Negative forecasts will allow enterprise management to assess the risks of investing in energy saving and identify ways to increase it.
To establish the hierarchical relations of factors influencing the decision-making process for the formation of energy saving policy at the enterprise, their classification has been performed on the following features: external factors of direct influence, and indirect influence, internal factors of direct influence (Fig. 1).

Having considered the expediency of implementing energy saving policy at the system level, the linguistic variable $\mathrm{W}$, which characterizes the investment expediency of implementing energy saving policy at the enterprise, can be represented as the ratio:

$$
W=f\left(a_{1}, a_{2}, a_{3}, a_{4}, b_{1}, b_{2}, b_{3}, b_{4}, c_{1}, c_{2}, c_{3}, c_{4}\right) \text {, }
$$

where $W$ is an indicator of the efficiency of implementation of energy saving policy at the enterprise; $a-$ is a linguistic variable describing the influence of factors of external indirect influence; $b-$ is a linguistic variable, describing the influence of factors of external direct influence; $c$ - is a linguistic variable, describing the influence of internal factors of direct influence.

Figure 1 shows the tree of a logical conclusion, the root of which corresponds to the indicator of the efficiency of the implementation of energy saving policy, and the hanging vertices are the factors of influence. Also Figure 1 shows a universal set of linguistic evaluation of each factor of influence in points. In linguistic terms, each factor is evaluated by the terms $L$ - low, $b A$ - below average, $A$ average, $a A$ - above average and $H$ - high.

In this article the functions of the appliance by the Gaussian form have been used. Knowledge bases are filled with expert information. The processing of expert information has been carried out according to well-known methods $[15 ; 22]$. Two knowledge bases have been formed the main one used to form a fuzzy model and the training received after the implementation of the model.

The mathematical model of the expert-modeling system for multifactorial analysis of decision-making processes on the efficiency of the energy policy of enterprises has been presented in the form of a set of fuzzy logical equations, information in which corresponds to the basic knowledge bases. All fuzzy equations correspond to the content of knowledge bases. A fragment of the mathematical model is given below:

$\mu^{b A}\left(a_{1}\right) \wedge \mu^{A}\left(a_{2}\right) \wedge \mu^{A}\left(a_{3}\right) \wedge \mu^{b A}\left(a_{4}\right) \wedge \mu^{b A}\left(b_{1}\right) \wedge \mu^{b A}\left(b_{2}\right) \wedge$ $\mu^{a A}\left(b_{3}\right) \wedge \mu^{A}\left(b_{4}\right) \wedge \mu^{b A}\left(c_{1}\right) \wedge \mu^{b A}\left(c_{2}\right) \vee \mu^{A}\left(c_{3}\right) \wedge \mu^{A}\left(c_{4}\right) \vee$ $\mu^{L}\left(a_{1}\right) \wedge \mu^{L}\left(a_{2}\right) \wedge \mu^{b A}\left(a_{3}\right) \wedge \mu^{b A}\left(a_{4}\right) \wedge \mu^{b A}\left(b_{1}\right) \wedge \mu^{A}\left(b_{2}\right) \wedge$ $\mu^{b A}\left(b_{3}\right) \wedge \mu^{L}\left(b_{4}\right) \wedge \mu^{a A}\left(c_{1}\right) \wedge \mu^{A}\left(c_{2}\right) \vee \mu^{A}\left(c_{3}\right) \wedge \mu^{b A}\left(c_{4}\right) \vee$ $\mu^{a A}\left(a_{1}\right) \wedge \mu^{A}\left(a_{2}\right) \wedge \mu^{B C}\left(a_{3}\right) \wedge \mu^{C}\left(a_{4}\right) \wedge \mu^{L}\left(b_{1}\right) \wedge \mu^{b A}\left(b_{2}\right) \wedge$ $\mu^{A}\left(b_{3}\right) \wedge \mu^{A}\left(b_{4}\right) \wedge \mu^{b A}\left(c_{1}\right) \wedge \mu^{a A}\left(c_{2}\right) \wedge \mu^{H}\left(c_{3}\right) \wedge \mu^{H}\left(c_{4}\right)=$ $=\mu^{b A}(W)$;

$\mu^{a A}\left(a_{1}\right) \wedge \mu^{a A}\left(a_{2}\right) \wedge \mu^{A}\left(a_{3}\right) \wedge \mu^{a A}\left(a_{4}\right) \wedge \mu^{A}\left(b_{1}\right) \wedge \mu^{A}\left(b_{2}\right) \wedge$ $\mu^{A}\left(b_{3}\right) \wedge \mu^{a A}\left(b_{4}\right) \wedge \mu^{A}\left(c_{1}\right) \wedge \mu^{A}\left(c_{2}\right) \vee \mu^{a A}\left(c_{3}\right) \wedge \mu^{b A}\left(c_{4}\right) \vee$ $\mu^{a A}\left(a_{1}\right) \wedge \mu^{a A}\left(a_{2}\right) \wedge \mu^{H}\left(a_{3}\right) \wedge \mu^{A}\left(a_{4}\right) \wedge \mu^{A}\left(b_{1}\right) \wedge \mu^{b A}\left(b_{2}\right) \wedge$ $\mu^{A}\left(b_{3}\right) \wedge \mu^{A}\left(b_{4}\right) \wedge \mu^{a A}\left(c_{1}\right) \wedge \mu^{b A}\left(c_{2}\right) \vee \mu^{A}\left(c_{3}\right) \wedge \mu^{b A}\left(c_{4}\right) \vee$ $\mu^{H}\left(a_{1}\right) \wedge \mu^{b A}\left(a_{2}\right) \wedge \mu^{B}\left(a_{3}\right) \wedge \mu^{A}\left(a_{4}\right) \wedge \mu^{H}\left(b_{1}\right) \wedge \mu^{A}\left(b_{2}\right) \wedge$ $\mu^{H}\left(b_{3}\right) \wedge \mu^{6 A}\left(b_{4}\right) \wedge \mu^{A}\left(c_{1}\right) \wedge \mu^{b A}\left(c_{2}\right) \wedge \mu^{L}\left(c_{3}\right) \wedge \mu^{H}\left(c_{4}\right)=$ $=\mu^{A}(W)$; 


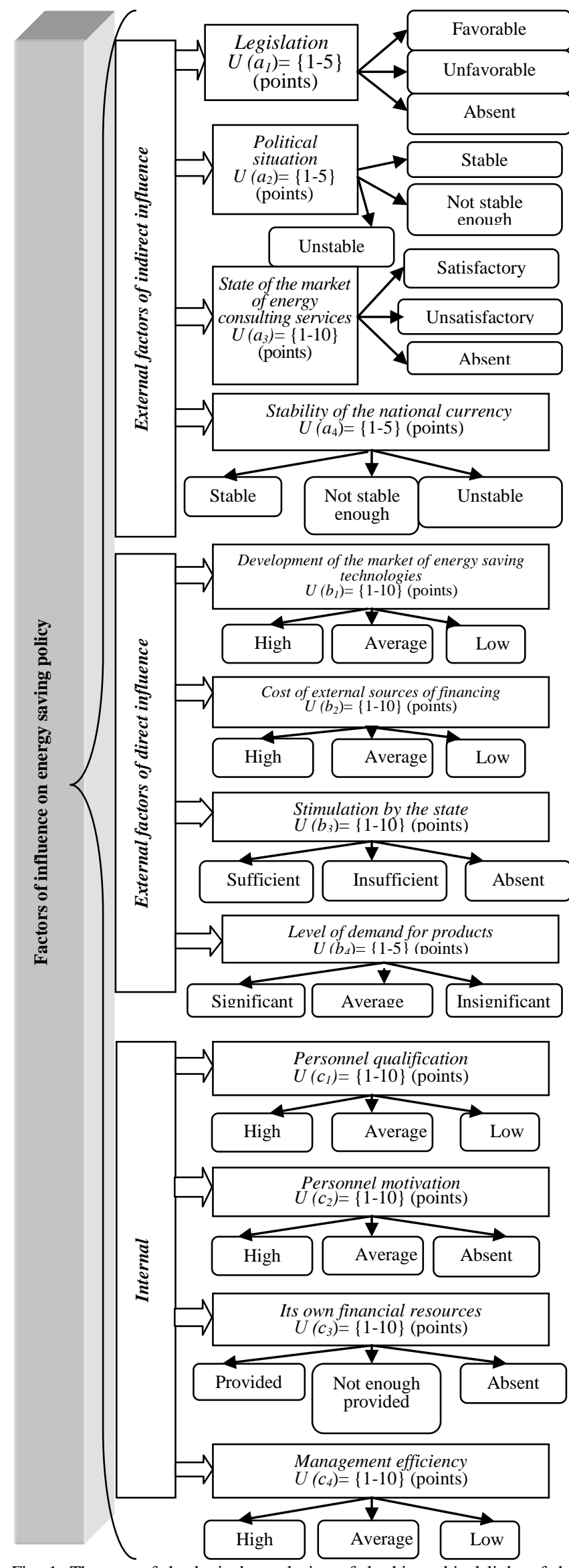

Fig. 1. The tree of the logical conclusion of the hierarchical links of the factors influencing the decision-making process on the expediency of implementation of the energy saving policy at the enterprise
The structure of the neural-fuzzy hybrid network is generated through sub-active clustering by the mountain method (Fig. 2).

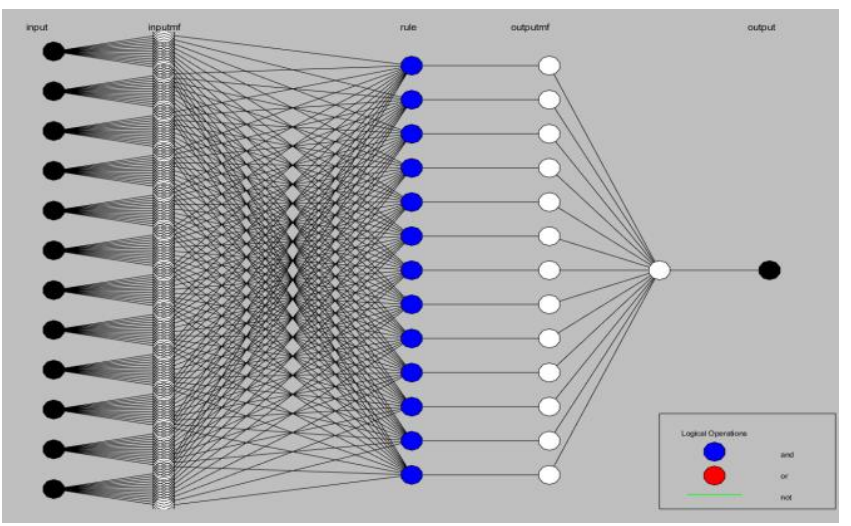

Fig. 2. Structure of neural-fuzzy hybrid network generated through subactive clustering by the mountain method

The surface of reviews of the neural-fuzzy hybrid network is shown in Figure 3.

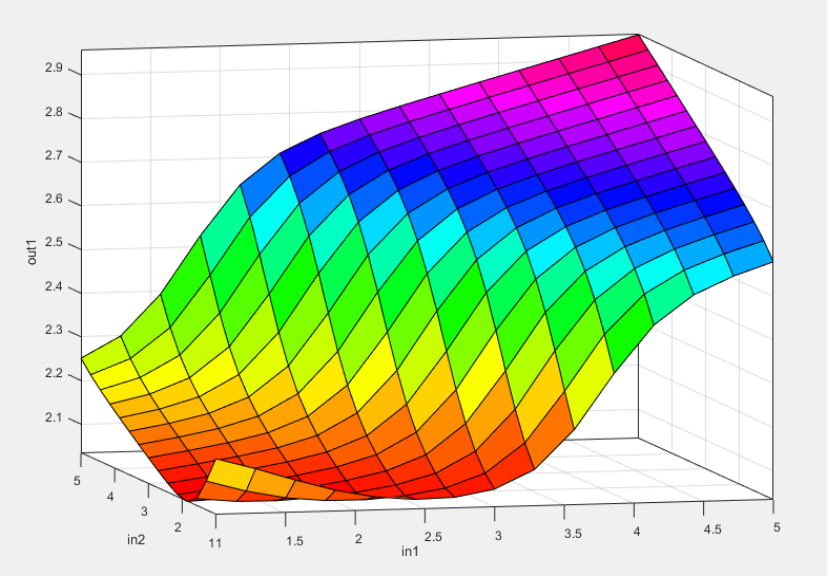

Fig. 3. The surface of reviews of neural-fuzzy hybrid network

The practical use of the obtained mathematical model is to determine the value of the efficiency indicator of implementation of energy saving policy at the enterprise, depending on the initial conditions. According to the value of this indicator, one can make a conclusion about the efficiency of implementing energy saving policy at the enterprise and, in general, on the feasibility of its implementation.

Implementation of the provisions of the proposed approach was carried out at a number of Ukrainian enterprises; in particular, the following companies were subjected to the analysis of the efficiency of the implementation of energy saving policy: "Vatis" Ltd., Vinnytsia, "Gran" Ltd., Korosten, "Eximbud" Ltd., Vinnytsia. Output data and modeling results taking into account the economic situation in the country [20] are presented in Table 1. Output data were obtained expertly during the questioning of experts-energy auditors and specialists of the enterprise itself. All enterprises work in the construction industry, produce the same type of products and therefore the value of the factors of external direct and indirect influence in them are similar. The differences lie in 
the orientation of energy-saving policy, depending on the specialization of the enterprise.

TABLE I. OUTPUT DATA AND RESULTS OF MODELING THE DETERMINATION OF EFFICIENCY OF ENERGY SAVING POLICY AT THE ENTERPRISE

\begin{tabular}{|c|c|c|c|c|c|c|c|c|c|c|c|c|c|}
\hline \multirow[b]{2}{*}{ 氡 } & \multicolumn{12}{|c|}{ Value of factors of influence } & \multirow[b]{2}{*}{ 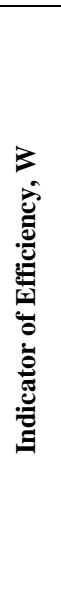 } \\
\hline & 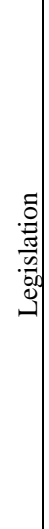 & 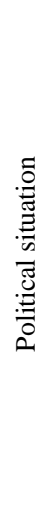 & 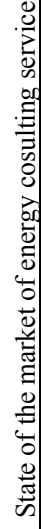 & 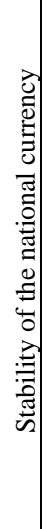 & 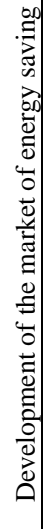 & 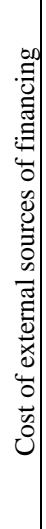 & 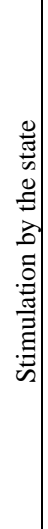 & $\begin{array}{l}0 \\
0 \\
0 \\
0 \\
0 \\
0 \\
0 \\
0 \\
0 \\
0 \\
0 \\
0 \\
0 \\
4 \\
0 \\
0 \\
0 \\
0 \\
0\end{array}$ & 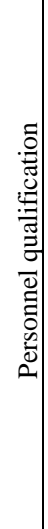 & 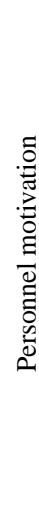 & 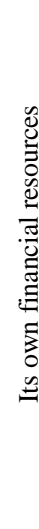 & $\begin{array}{l}0 \\
0 \\
0 \\
0 \\
0 \\
0 \\
0 \\
0 \\
0 \\
0 \\
0 \\
0 \\
0 \\
0 \\
\Sigma \\
0 \\
0\end{array}$ & \\
\hline $\begin{array}{l}\text { "Vatis" } \\
\text { Ltd }\end{array}$ & 4 & 4 & 3 & 4 & 4 & 5 & 3 & 4 & 5 & 3 & 4 & 4 & 4,0 \\
\hline $\begin{array}{l}\text { "Gran" } \\
\text { Ltd }\end{array}$ & 3 & 4 & 2 & 4 & 3 & 4 & 3 & 1 & 3 & 2 & 5 & 3 & 2,72 \\
\hline $\begin{array}{l}\text { "Exim- } \\
\text { bud" } \\
\text { Ltd }\end{array}$ & 4 & 4 & 2 & 4 & 1 & 2 & 3 & 2 & 4 & 2 & 3 & 1 & 2,44 \\
\hline
\end{tabular}

As a result of modeling, it has been found that despite the almost identical conditions of operation, the significant influence on the final result is due to the conditions of the internal environment of the enterprise and external factors of direct influence. According to the results, the most favorable conditions for the implementation of energy saving policy were created by "Vatis" Ltd., the worst - by "Eximbud" Ltd., the difference between the values of indicators is 1.64 times.

\section{CONCLUSIONS AND PROPOSALS}

Consequently, in this paper a mathematical model of intellectual support of decision making for the evaluation of the efficiency of the implementation and operation of the energy saving policy of the enterprise under uncertainty with the help of Mat Lab's mathematical package has been developed. The main factors influencing the decision making process regarding the feasibility of implementing energy saving policy at the enterprise have been determined. Using the proposed mathematical model will allow assessing the efficiency of creating energy saving policy at the enterprise, comparing single-type and diverse enterprises in this position, and concluding that it is expedient to invest in energy saving measures of a particular enterprise or a number of enterprises.

\section{REFERENCES}

[1] V. M. Heyets, "Development and interaction of economic and energy policy in Ukraine" Bulletin of the National Academy of Sciences of Ukraine, Vol. 2, pp. 46-53, 2016 [in Ukrainian].

[2] B. P. Gevko, V.Ya. Brich, Yu. V. Dzyadykevych, B. V. Pogrischuk, and A. M. Alileuko, "Directions of increase of efficiency of functioning of enterprises of housing and communal services", Bulletin of the Engineering Academy of Ukraine, vol. 2, pp.125-130, 2017. [in Ukrainian].
[3] M. A. Yokhna, O. A. Mikoluk, and V. V. Stadnyk, Management of energy efficiency of the enterprise, Khmelnytskyi: KhNU, 2012. [in Ukrainian].

[4] V. V Stadnik., and O. A. Mikolyuk, "Problems of energy consumption efficiency of machine-building enterprises and ways of their solution", Bulletin of the National University of Water Management and Nature Management, vol. 1, pp. 191-200, 2011. [in Ukrainian].

[5] V. M. Nizhnik, and T. V. Shumovetska, "Efficient Resource and Energy Conservation in the System of Economy Cost of Production and Industrial Enterprises", Bulletin of the Khmelnitsky National University. Economic Sciences, vol. 3, no. 3, pp. 100-102, 2012 [in Ukrainian].

[6] E. Worrell, J. A. Laitner, M. Ruth, and H. Finman, "Productivity benefits of industrial energy efficiency measures", Energy, vol. 28 (11), pp. 1081-1098, 2003, http://www.sciencedirect.com/ science/article/pii/S0360544203000914. Accessed on: July 10, 2019.

[7] K. Vikhorev, R. Greenough, and N. Brown, "An advanced energy management framework to promote energy awareness", Journal of Cleaner Production, vol. 43, no. 1, pp. 103-112, 2013. https://doi.org/10.1016/j.jclepro.2012.12.012

[8] D. Lee, and C. C. Cheng, "Energy savings by energy management systems: A review", Renewable and Sustainable Energy Reviews, vol. 56, no. 2, pp. 760-777, 2016.

[9] V. V. Mykytenko, Energy efficiency of industrial production, Kyiv : Unite Institute of Economics, National Academy of Sciences of Ukraine, 2005. [in Ukrainian].

[10] P. Thollander, P. Rohdin, and B. Moshfegh, "On the formation of energy policies towards 2020: challenges in the Swedish industrial and building sectors". Energy Policy, no. 4, pp. 461-467, 2012, DOI: http://dx.doi.org/10.1016/j.enpol.2011.12.012

[11] C. Păunescu, and L. Blid, "Effective energy planning for improving the organization's energy performance", Management \& Marketing. Challenges for the Knowledge Society, vol. 11, no. 3, pp. 513-531, 2016, DOI: https://doi.org/10.1515/mmcks-2016-0013

[12] Yu. D. Kostin, V. M. Bezlepkin, "Pricing factors of energy saving at FEC enterprises", Bulletin of Economic Science of Ukraine, no. 1, pp. 70-73, 2012, http://dspace.nbuv.gov.ua/handle/123456789/44738

[13] O. V. Kyrylenko, "Energy saving - development strategy", Business Bulletin, vol. 2, pp. 8-11, 2010. [in Ukrainian].

[14] J. Pearl, Bayesian networks: A Model of Self-Activated Memory for Evidential Reasoning (UCLA Technical Report CSD-850017), Handbook of Brain Theory and Neural Networks, MIT Press, 2001. . [Online]. Available: ftp://ftp.cs.ucla.edu/pub/stat_ser/R277.pdf. Accessed on: May 28, 2019

[15] L. Zade, The concept of a linguistic variable and its application to the adoption of approximate solutions, Moscow. : Mir, 1976. [in Russian].

[16] V. V. Kulazhenko, "Possibilities of Application of Artificial Neural Networks in the System for Monitoring the Economic Security of the Enterprise", Visnyk Berdyansky Institute of Management and Business, vol. 2, pp. 100-103, 2012. [in Ukrainian].

[17] A. V. Matviychuk, Artificial Intelligence in Economics: Neural Networks, Fuzzy Logic, Kyiv : KNEU, 2011. [in Ukrainian].

[18] M. P. Voynarenko, and O. A. Mykolyuk, "Strategic energy security outlook formation of Ukraine under European integration process", Scientific Bulletin of Polissia, vol. 3(11), no. 1, pp. 29-37, 2017.

[19] V. Dzhedzhula, and I. Yepifanova, "Use of apparatus of hybrid neural networks for evaluation of an intellectual component of the energy-saving policy of the enterprise" Baltic Journal of Economic Studies, vol. 4, no. 1, pp. 126-130, 2018

[20] J. C. Brunke, M. Johansson, and P. Thollander, "Empirical investigation of barriers and drivers to the adoption of energy conservation measures, energy management practices and energy services in the Swedish iron and steel industry". J. Clean. Prod., No. 84, pp. 509-525, 2014, doi:10.1016/j.jclepro.2014.04.078

[21] Official site of the State Statistics Service of Ukraine. [Online]. Available: http://www.ukrstat.gov.ua. Accessed on: May 29, 2019.

[22] S. D. Shtovba, Designing Fuzzy Systems by Matlab Tools, Moscow: Hotline - Telecom, 2007. [in Russian]. 